\title{
MEDICINA PARA ANIMALES EN LA CATALUÑA DEL SIGLO XVIII: UNA PRÁCTICA MÉDICA PLURAL
}

\author{
Alfons Zarzoso \\ Conservador del Museu d'Història de la Medicina de Catalunya, Barcelona
}

\section{RESUMEN}

El artículo desarrolla un marco de trabajo para comprender el mundo de la medicina de los animales en la Cataluña del siglo XVIII. El análisis del contexto histórico permite conocer las actuaciones de las autoridades borbónicas en materia de fomento y control del ejercicio de aquella medicina. Una aproximación antropológica ofrece la posibilidad de acceder a un complejo entramado plural de recursos médicos disponibles, al alcance de aquellos individuos interesados en la salud de los animales.

PALABRAS CLAVE: Medicina, Albeitería, menescal, antiguo régimen, Cataluña, España, siglo XVIII.

\section{ANIMALS AND MEDICINE IN $18^{\mathrm{TH}}$ CENTURY CATALONIA: A PLURAL MEDICAL PRACTICE}

\section{ABSTRACT}

This article proposes a framework in order to understand the animal medical world in 18thcentury Catalonia. By focusing in that historical context, we try to reveal the Bourbon policy on the matter of animal health. Through an anthropological lens we can observe a real complex and plural world of medical resources available to those individual interested in the health of animals.

KEY WORDS: Medicine, Veterinary, menescal, old regime, Catalonia, Spain, $18^{\text {th }}$-century.

\section{INTRODUCCIÓN ${ }^{1}$}

La historia de la medicina animal tiene todavía un largo recorrido por delante. Las páginas que siguen pretenden contribuir a proporcionar algunas

1 Una primera versión de este trabajo, ahora ampliada, fue discutida en el marco del simposio «Ramaderia, veterinària i consum de carn a Catalunya, segles XIV-XIX», véase: ZARzoso, A. (2002), «Animals i menescalia a la Catalunya del segle XVIII». En: BATLLÓ. J. 
bases para comprender esta historia en la Cataluña del siglo XVIII. Este trabajo entronca con otros análisis que se están produciendo en los últimos años sobre esta cuestión en el período anterior, desde la Baja Edad Media hasta el siglo XVII, y en el período inmediatamente posterior, centrado en el siglo XIX. Nos ha parecido pertinente iniciar el artículo haciendo referencia al contexto histórico en el que tuvo lugar nuestro ámbito de estudio, ya que ello nos ha de permitir valorar mejor la situación de la ganadería en Cataluña, así como el papel de las autoridades y de los expertos en la medicina de los animales. A partir del contexto histórico señalado, este trabajo plantea una aproximación al pluralismo existente en aquella sociedad en materia de recursos disponibles para hacer frente a la enfermedad en los animales. Desde una perspectiva antropológica, en este trabajo se presta una atención especial a aquel complejo entramado de recursos y a los ámbitos de intersección y de competición que se abrían a los ojos de los interesados. En la parte final del artículo, se intenta poner de manifiesto cómo el contexto histórico marcado por las políticas de los Borbones limitó y retrasó la transformación de la medicina de los animales mediante decisiones y reformas que, más allá de su supuesto carácter modernizador, no hicieron más que aumentar la conflictividad existente, sin estimular la formación o recepción de los presupuestos teóricos y prácticos que tenían lugar en Europa desde el último tercio del siglo XVIII.

Los manuales de historia suelen proporcionar una imagen dual de la Cataluña del siglo XVIII, según la perspectiva sea política o económica. Por una parte, el resultado final de la guerra de Sucesión supuso la imposición de una Nueva Planta política y administrativa al suprimir las instituciones de gobierno tradicionales, junto con todo el entramado político, jurídico, administrativo y legislativo catalán, imponiéndose el propio de Castilla. Por otra, el rumbo seguido por la economía catalana desde finales del siglo XVII experimentó un empuje a lo largo del siglo XVIII, a partir de una expansión agraria que favoreció el desarrollo comercial y consolidó las bases y redes de las manufacturas catalanas. Aunque esta sucinta caracterización resulta una simplificación obvia, nos permite plantear si este proceso de transformación afectó durante este período a la ganadería y al ejercicio de la albeitería en la Cataluña del siglo XVIII².

et al. Actes de la VI Trobada d'Història de la Ciència i de la Tècnica, Barcelona, SCHCT, 107-118. Jon Arrizabalaga y Pepe Pardo leyeron y apuntaron el texto con amabilidad. Quisiera agradecer también los comentarios realizados por los evaluadores externos de la revista, pues han mejorado un trabajo, cuyos errores son por supuesto responsabilidad del autor.

2 Con el nombre menescalia - albeitería en castellano - se conocía en los territorios de lengua catalana de la Corona de Aragón la tarea desarrollada por el menescal —albéitar-, 
La historia de la economía catalana ha mostrado cómo se formaron, entre finales del siglo XVII y comienzos del siglo XIX, las bases necesarias para la adopción de un sistema de desarrollo capitalista. Esta transformación económica fue posible a partir de la combinación de cuatro factores básicos: avance demográfico, expansión de la agricultura, crecimiento manufacturero e incremento del volumen de intercambios. Cabe recordar cómo tres de estos elementos afectaron directamente a la ganadería catalana. En primer lugar, la expansión agraria catalana contribuyó a la progresiva marginación de la ganadería ya que su desarrollo se basó, de manera especial, en una extensión de los cultivos, con la consiguiente colonización de tierras mediante la deforestación, la desecación o el uso de tierras comunales y en una especialización basada en la apuesta por los cultivos más rentables en cada lugar - destacando la viña y sus frutos como producto central de los intercambios. Esto se hizo evidente en la reducción constante de los pastos disponibles y en el cierre de los tradicionales pasos de tránsito, por tanto en la limitación de la ganadería trashumante, y también en el aumento de los conflictos provocados por la presencia destructiva del ganado en los campos de cultivo, por tanto en el incremento de los costes ganaderos al haber de pagar multas por la destrucción de los cultivos o tener que contratar más pastores para evitar tales incidentes. En segundo lugar, el impulso de la industria algodonera desde los años 1760-1780 jugó un papel clave a partir de su difusión progresiva en las comarcas donde previamente se había desarrollado la tradicional manufactura de la lana. La versatilidad de las economías tradicionales ante las nuevas opciones favoreció el desequilibrio en el consumo de materias primas - algodón vs. lana- $\mathrm{y}$, por tanto, contribuyó a una reducción de la demanda de productos derivados del ganado de lana. Como dejó escrito Pierre Vilar, «en Cataluña la ganadería tienta cada vez menos a la empresa: no es un complemento obligado de los cultivos mediterráneos más estimados». En tercer lugar, la especialización agraria actuó como factor de activación de la circulación mercantil anterior y exterior, dada la necesidad de importar cada vez más productos de subsistencia y de vender los productos de intercambio. En Cataluña, el sistema de comunicación básico para soportar un intenso tráfico de mercancías fue el camino de herradura, que junto a la mula y el arriero constituyeron la columna vertebral de la economía catalana hasta mediados del siglo XIX. Como con-

persona que tenía por oficio curar las enfermedades de los animales. Estas denominaciones continuaron en uso hasta bien entrado el siglo XIX. Véase: Cifuentes, L., Ferragud, C. \& GARCÍA BALLESTER, L. (1999), «Els menescals i l'art de la menescalia a la Corona d'Aragó durant la Baixa Edat Mitjana». En: Història de la ramaderia i la veterinària als Països Catalans. Actes del IV Col-loqui d'Història Agrària, Barcelona, CEHI-UB, 75-98. 
secuencia del desarrollo e impacto de estos elementos, la capacidad competitiva de los ganaderos catalanes ante el extraordinario crecimiento del mercado de consumo de carne en Barcelona se vio prácticamente anulada. El negocio de la carne de consumo permaneció en manos de las grandes redes barcelonesas del comercio de importación y exportación de mercancías y lejos, por tanto, de las posibilidades de control de los ganaderos catalanes ${ }^{3}$.

A finales del siglo XVIII, los testimonios coetáneos (Zamora, Baró de Maldà, Caresmar) confirmaron esta imagen: la falta de pastos, provocada por las grandes roturaciones, por la expansión de la viña y por la progresiva desaparición del barbecho y de los comunales había agravado la situación ya decadente de la cabaña catalana. La Junta de Comerç de Barcelona (1758), institución que representaba los intereses de la burguesía comercial catalana, patrocinó la publicación del texto conocido como Discurso (1780), donde se abunda en la idea de la constante disminución de la cabaña. Una frase predominante utilizada con relación al ganado es: «la falta de pastos no permite su aumento». A su vez, el Discurso destaca la limitación de la cría, en la mayoría de los corregimientos catalanes, a los animales destinados a las carnicerías locales, al sacrificio excesivo y perjudicial del ganado joven con el fin de satisfacer la demanda creciente del mercado catalán y, finalmente, a la progresiva insuficiencia de la ganadería catalana para satisfacer el mercado barcelonés. Cabría añadir a la percepción de estos testigos una nota sobre el carácter del pensamiento agrario dominante en Cataluña. El pensamiento de hombres como Romà i Rossell, Caresmar, Sisternes y los agraristas de la Junta de Comercio y de la Real Academia de Ciencias y Artes de Barcelona: fiel a la pragmática combinación de ideas liberales e intervencionistas, consciente del papel decisivo que el aumento de la producción agraria especializada estaba jugando en el desarrollo económico de Cataluña. Por todo ello, la cuestión de la ganadería se planteó desde el punto de vista del equilibrio de la balanza

3 Sobre estos aspectos, véase: VILAR, P. (1986), Catalunya dins l'Espanya Moderna, Barcelona, Curial-Edicions 62, vol. II, 115-248, La cita de la p. 156: «la ramaderia a Catalunya tempta cada vegada menys l'empresa: no és un complement obligat dels conreus mediterranis més estimats»; MARTíNEZ SHAW, C. (1985), «La Cataluña del siglo XVIII bajo el signo de la expansión». En: FernÁNDEZ, R. (ed.), España en el siglo XVIII. Homenaje a Pierre Vilar, Barcelona, Crítica, 55-131; SALES, N. (1991), Mules, ramblers i fires (s. XVIII-XIX), Reus, Centre de Lectura, 15-42; FonTANA, J. (1988), La fi de l'Antic Règim i la industrialització, 1787-1868, Barcelona, Edicions 62, 57-91, vol. V de la Història de Catalunya dirigida por Pierre Vilar; AlBaredA, J. (1995), Desfeta política i embranzida econòmica. Segle XVIII, Barcelona: Enciclopèdia Catalana, 31-43 y 268-276, vol. 5 de la Història, política, societat $i$ cultura dels Països Catalans. 
comercial catalana. Atendiendo a la rentabilidad de la agricultura, se hacía necesario equilibrar las importaciones de ganado hechas para satisfacer la demanda del mercado catalán con la venta de otros productos agrarios y manufacturados. A la vez, se debían poner en práctica otras medidas - creación mediante regadíos de nuevos pastos, introducción de plantas forrajeras, prohibición de roturaciones en los comunales destinados a pastos- para fomentar al menos la cría de ganado estabulado con el que compensar, siquiera parcialmente, el escaso consumo de carne autóctona.

Como resultado de esta apuesta de desarrollo económico, la comprometida situación de los ganaderos catalanes forzó la importación de numerosas cabezas de ganado, tanto para el consumo humano y el de determinadas actividades productivas como para satisfacer las necesidades de transporte. Aragón, Valencia y en menor medida Castilla comercializaron sus ganados en Cataluña. Fue Francia, sin embargo, la gran exportadora de ganado vacuno, de lana, mayor y de pata hendida destinado al mercado catalán ${ }^{4}$.

La situación de la ganadería catalana del siglo XVIII quedaba concretada, según lo expuesto, en una cabaña autóctona cada vez más limitada al consumo local y particular y en un tránsito constante de cabezas de ganado, mayoritariamente importado, bien a las carnicerías y ferias locales, bien transportando mercancías, soldados y trenes de artillería por toda Cataluña. Una vez apuntado el contexto histórico, conviene a continuación plantear cómo se caracterizó la medicina de los animales con el objetivo añadido de observar cuáles fueron las modificaciones introducidas por la Nueva Planta política y administrativa y cuál fue la respuesta de las autoridades ante las enfermedades del ganado.Por razones de espacio, vamos a limitar el presente estudio a arrojar alguna luz

4 Sobre estas cuestiones, véase: VILAR (1986), 118-127 y 156-163; LLUCH, E. (1996), La Catalunya vençuda del segle XVII. Foscors i clarors de la Il·lustració, Barcelona, Edicions 62; Lluch, E. \& ARgemí, L. (1985), Agronomía y fisiocracia en España, 1750-1820, València, Institució Alfons el Magnànim, 1-43 y 45-100; LLuCH, E. (ed.), (1997), Junta de Comerç, Discurso sobre la agricultura, comercio e industria del Principado de Cataluña (1780), Barcelona, Alta fulla, 223, 231-2, 247, 263-5, 269, 273, 283, 289-90, 308, 311, 315, 326, 336-8, 347, 358-9, 364, 371; SALES, N. (1991), 45-69; LlOMBART, V. (1989), «Comparación entre los ilustrados de la Corona de Aragón y los de Castilla y León. Campomanes, Sisternes y Assó ante la Ley Agraria» y ARGEMí, L. (1989), «Nueva agronomía y agrarismo en la España Ilustrada». Ambos en: Estructuras agrarias y reformismo ilustrado en la España del siglo XVIII, Madrid, Ministerio de Agricultura, Pesca y Alimentación, 539-552 y 553-563; BERNAT, P. (2000), «La Direcció d'Agricultura de la RACAB (1766-1808)». En: NIETO-GALAN, A. \& Roca Rosell, A. (coords.), La Reial Acadèmia de Ciències $i$ Arts de Barcelona als segles XVIII i XIX, Barcelona: RACAB-IEC, 221-231. 
sobre la primera de las cuestiones, dejando para una ulterior publicación el análisis de las actuaciones y de las medidas dictadas por las autoridades ante las enfermedades epidémicas del ganado.

\section{APUNTE METODOLÓGICO}

Los animales y, de manera más concreta, la historia de la medicina de los animales, apenas han constituido objeto de atención e investigación histórica en el marco de un proyecto de construcción de una disciplina y un quehacer de carácter profesional. Probablemente esto ha contribuido al escaso desarrollo de la medicina animal como categoría de análisis histórico e historiográfico. Resulta un hecho notable constatar, a pesar de la existencia de elementos comunes y salvando los diferentes volúmenes de ocupación, la escasa relación entre los historiadores de la medicina humana y los de la medicina animal. Tal vez ello responde, desde una perspectiva cultural, a la asunción ideológica de la superioridad del hombre sobre el resto de animales. En cualquier caso, el desinterés mutuo y la correlativa parcelación de las ciencias de la salud no han favorecido una mejora de nuestro conocimiento sobre la relación entre los hombres y los animales en el pasado. Tampoco ha venido a ayudar la construcción de una débil y tardía tradición historiográfica veterinaria, tanto en el plano internacional como en el español, sumida con frecuencia entre la búsqueda de legitimación histórica de sus saberes y el afianzamiento de posiciones versus la medicina. Parece necesario un mayor compromiso de los historiadores de la ciencia sobre la necesidad de producir estudios que consideren la relación hombre-animales como categoría de análisis histórica. También parece oportuno ir más allá de una historia que busca «nuestras raíces»o que se centra en «nuestra profesión». En este sentido, se debería ir más allá de esa historia de actitudes que situaba la frontera entre la ignorancia y el progreso científico a partir del establecimiento de las escuelas de veterinaria a finales del siglo XVIII, que consideraba aquel contexto de cambio como el punto de partida del desarrollo de la veterinaria científica y de la profesión veterinaria. La superación de tal interpretación nos permitirá probablemente comprender mejor la compleja historia, también anterior a la creación de aquellas escuelas, de las relaciones entre los hombres y los animales, entre la medicina humana y la medicina animal ${ }^{5}$.

5 Para una reflexión sobre las relaciones entre la historia de la medicina humana y animal en un contexto de aproximación entre los historiadores de uno y otro ámbito, véase: POR- 
En nuestra aproximación al mundo médico de los animales en la Cataluña del siglo XVIII partimos de un esquema interpretativo que fija la atención en las dimensiones culturales - popular, médica y religiosa - a la hora de intentar comprender el comportamiento humano ante las enfermedades de los animales. ${ }^{6}$ En la investigación sobre la medicina para la salud de los animales resulta fundamental no reducir el análisis a un único recurso, en este caso el albéitar, entre las diversas posibilidades de curación. En efecto, la medicina animal, como la medicina humana, también se debe entender en función de las coordenadas del pluralismo médico existente en la sociedad de antiguo régimen. Es decir, a partir del estudio de todas aquellas personas que según el interesado - la persona que posee o cuida del animal - estaban específicamente formadas, experimentadas y/o dotadas de forma natural para resolver los problemas de salud y enfermedad. La utilidad de este acercamiento permite obtener una perspectiva más comprensiva del fenómeno al mostrar las dimensiones sociocultural y económica en el momento de la toma de decisiones y elecciones ante la enfermedad. La formación de una cultura médica individual no sólo pone así de manifiesto la existencia, superposición e interacción de una miríada de recursos disponibles, que se hallan en el modelo antropológico de las esferas médica, religiosa y popular descrito por David Gentilcore, sino que además permite plantear la cuestión del cambio histórico a partir del análisis de los fenómenos paralelos de negociación, regulación y represión que tienen lugar en el marco de la lucha por obtener la hegemonía en el mundo de la medicina animal ${ }^{7}$.

TER, R. (1993), «Man, Animals and Medicine at the time of the founding of the Royal Veterinary College». En: A.R. Michell (ed.), The Advancement of Veterinary Science, vol. III de la History of the Healing Professions. Parallels between Veterinary and Medical History, Oxon, CAB International, 19-30. Baste como ejemplo del tipo de historiografia veterinaria a la que me he referido, el siguiente volumen colectivo: SUÁREZ, G. (ed.) (1994), Libro conmemorativo del Bicentenario de la Facultad de Veterinaria, 1793-1993, Madrid, Editorial Complutense, 17-64.

6 La utilitad analítica de este planteamiento teórico ha sido desarrollada con acierto en el estudio sobre la pluralidad médica de Nápoles durante la época moderna. Véase: GENTILCORE, D. (1998), Healers and healing in early modern Italy, Manchester-New York, Manchester U.P., 1-28, 56-124 y 156-176. Sobre el concepte de mundo médico, véase: BROCKLISS, L. \& JONES, C. (1997), The Medical World of early modern France, Oxford, Clarendon Press, 1-33.

7 Este acercamiento metodológico ha sido planteado en anteriores trabajos, véase: ZARzoso, A. (2001), «El pluralismo médico a través de la correspondencia privada en la Cataluña del siglo XVIII», Dynamis, 21, 409-433; ZARZOSo, A. (2003), «Mediating Medicine through Private Letters: the Eighteenth-Century Catalan Medical World». En: De BLÉCOURT, W. \& Usborne, C. (eds.), Cultural Approaches to the History of Medicine. Mediating Medicine in Early Modern and Modern Europe, Basingstoke, Palgrave Macmillan, 108-126; ZARZoso, A. (2006), L'exercici de la medicina a la Catalunya de la Il·lustració, Manresa, PAHCS, cap. 2. 
Ante la enfermedad humana, el primer nivel de la cultura médica individual en el mundo del antiguo régimen estaba formado por los consejos de la familia y de las amistades. Esta era la primera forma de expresión de la presencia de la enfermedad y, mediante los consejos y las recomendaciones, abría la puerta a los recursos terapéuticos de las tres esferas mencionadas. Además, esto suponía la concesión de la iniciativa al interesado ante la enfermedad. Esto es, una posición de control en relación al experto. La ausencia de estudios en esta dirección constituye una dificultad a la hora de hallar ejemplos de estos recursos aplicados al caso de la medicina animal. Entre las fuentes que podrían subsanar esta situación, cabría plantear el estudio de los fondos patrimoniales de los poseedores de caballerías con la idea de hallar el interés personal y familiar ante las enfermedades de los animales con que comerciaban. ${ }^{8}$ En este sentido, también cabe señalar la importancia de todo el arsenal de terapéutica doméstica recogido en inventarios familiares, en recetarios culinarios o en manuales de medicina doméstica humana y animal, como por ejemplo el que hallamos en el texto conocido como Libro del Prior. La posibilidad de afrontar un conjunto de enfermedades, que se podrían considerar como menores, mediante la confección casera de remedios pone de relieve la complejidad y la pluralidad médica de la sociedad de antiguo régimen. Por ello, parece necesario intentar mostrar la presencia paralela de otros recursos a partir del estudio de las esferas médica, religiosa y popular9 9

\section{EL EJERCICIO DE LA MEDICINA PARA ANIMALES}

La presencia, formación y ejercicio del albéitar ha sido bien documentada en los territorios de la Corona de Aragón durante el período bajomedieval. Estos estudios han planteado los paralelismos existentes entre las teorías y prácticas de la medicina humana y de la medicina animal a partir de un mis-

8 A título de ejemplo de alguno de los fondos patrimoniales catalanes mencionados, cabe remitir al de la compañía comercial de feriantes y chalanes de Calaf. Véase: CUBELLS, J. \& Herrera, J. (1980), Inventario de los fondos comerciales del Archivo Histórico Provincial de Tarragona, Madrid, Ministerio de Cultura.

9 Aunque sólo sea a modo de ejemplo, conviene señalar el valor que tiene el estudio detallado de los inventarios familiares en materia de medicina doméstica. Véase: SALES, N. (1962), Una vila catalana del segle XVIII, Barcelona, Rafael Dalmau, 21-27. En cuanto al Libro del Prior, véase: AGustí, M. (1617), Llibre dels secrets d'agricultura, casa rústica i pastoril, Barcelona, Esteve Lliberós, edición facsímil producida en Barcelona, Alta fulla, 1988. 
mo cuerpo de doctrina basado en la tradición humoralista ${ }^{10}$. A pesar de los escasos trabajos centrados en el estudio de las prácticas de la medicina animal para el período moderno, parece razonable creer que la práctica de la albeitería continuó su desarrollo y expansión a partir de las raíces previamente existentes ${ }^{11}$. De hecho, ya en el siglo XVIII, los registros de la Real Audiencia borbónica permiten documentar la persistencia de aquella tradición centrada en la medicina de los animales. Parece evidente relacionar tal presencia - la confianza en el experto - con la extensión del compromiso de las autoridades por la salud de los ciudadanos a un interés semejante por la salud de los animales. El albéitar aparece en los registros de la administración borbónica de la misma manera que se despachaban documentos mencionando a médicos, cirujanos y boticarios. Esto es, a partir de la certificación administrativa, supuestamente obligatoria, para proceder a la ejecución del tradicional sistema de contratación de la conducta municipal — conducta de común-, así como de la mención de los conflictos generados a partir de la formalización o del ejercicio derivado de aquellos contratos. La fórmula contractual de las conductas de sirvientes públicos — de médicos, cirujanos, boticarios, albéitares, maestros de primeras letras - garantizaba la presencia del experto en la localidad en la que era contratado. A lo largo del siglo XVIII, la conducta continuó siendo un asunto de interés municipal en Cataluña. Sin embargo, la Real Audiencia borbónica intervino directamente en el asunto al tratarse de una materia que concernía al gobierno político y que incorporaba decisiones de

10 Parece conveniente insistir en la línea de estudios abierta por los historiadores de la ciencia y la medicina medievales. Véanse: CifUENTES (1999); CifUENTES, L. (2002), La ciència en català a l'Edat Mitjana i el Renaixement, Barcelona-Palma de Mallorca, UB-UIB, 145156; Ferragud, C. (2005), Medicina i promoció social a la Baixa Edat Mitjana (Corona d'Aragó, 1350-1410), Madrid, CSIC, 129-174. En esta misma línea, para el caso de las prácticas asociadas a los «farriers» y «horse-doctors» ingleses, véase: CURTH, L. H. (2003), «Seventeenth-century English Almanacs: transmitters of advice for sick animals». En: De BLÉCOURT \& USBORNE (eds.), 56-70.

11 Mediante una estrategia basada en la consideración de fuentes de archivo, más allá de los tratados de la veterinaria, Lluís Cifuentes ha puesto de manifiesto que, desde los siglos medievales, el alcance real de la práctica cotidiana de los albéitares iba más allá del caballo y de la nobleza. El estudio que Cifuentes plantea a partir del libro de cuentas de un albéitar rosellonés del siglo XVII vendría a confirmar una práctica profesional y social mucho más compleja de lo que se ha sostenido hasta ahora. Véase: CIFUENTES, L. (2002), «Cavalls, bous i vaques: sobre manescalia i agronomia a Catalunya entre l'Edat Mitjana i la Moderna». En: BATLló. J. et al., 87-91. Sobre este tema, conviene también remitir al estudio del tratado de albeitería de Arredondo: TeiXidó Gómez, F. \& TeIXIDó GómeZ, J. (2002), «Las Obras de Albeytería de Martín Arredondo», Asclepio, LIV-2, 165-180. 
alcance económico que afectaban al conjunto de la población. Así fue como las autoridades municipales quedaron obligadas a solicitar permiso a la Real Audiencia para proceder a la contratación de un albéitar. Los registros de la institución de gobierno borbónica muestran una gran cantidad de casos de demandas realizadas por los municipios catalanes con tal finalidad a lo largo de toda la centuria. Se trata, por tanto, de una fórmula similar a la de las conductas de otros practicantes de la medicina - médicos, cirujanos y boticarios-, que experimentaron un destacado crecimiento en Cataluña desde el último tercio del siglo XVII ${ }^{12}$.

Mediante el compromiso de la conducta, el albéitar se obligaba a asistir e intentar sanar a los animales domésticos de los vecinos del municipio contratante. Según el historiador de la veterinaria Vicente Dualde, esta obligación se limitaba de manera exclusiva a la asistencia del ganado mayor o de pezuña hendida - caballos, yeguas, burros, asnos, mulas, bueyes, vacas, carneros, ovejas, cabras y cerdos ${ }^{13}$.

Con el objetivo de fijar a los expertos en las poblaciones y de conseguir aquéllos una cierta seguridad económica, la documentación muestra la formalización general de conductas trienales o cuatrienales. Tampoco resulta extraño hallar conductas que se alargaron durante toda la vida profesional de un albéitar. En algunos casos, se pueden documentar conductas que pasaron de padres a hijos, dando lugar a ejemplos de sagas familiares de profesionales con clientelas locales estables. De hecho, la continuación de la conducta dependía, entre otros aspectos y más allá de la coyuntura económica, del cumplimiento del ejercicio por parte del albéitar y de su buena relación con los vecinos ${ }^{14}$.

12 Sobre las conducciones de médicos, cirujanos y boticarios en la Cataluña del siglo XVIII, véase: ZARZOSO (2006), cap. 3.

13 Sobre el ámbito de actuación en el caso valenciano, véase: DuALDE, V. (1997), Historia de la albeytería valenciana, València, Ajuntament de València, 379-402.

14 Este fue el caso de Isidre Roig, albéitar de la vila de Palau, en el corregimiento de Lleida, según se advierte en su petición de un cargo a la Real Audiencia, donde alegaba más de veinticinco años de práctica y ejercicio de la albeitería en la villa mencionada. Archivo de la Corona de Aragón (ACA, a partir de aquí), Real Audiencia (RA, a partir de aquí), Consultas, reg. 159, 123r-124r, Barcelona, 16/1/1738. Ejemplos de sagas de albéitares se pueden hallar en: LLEONART, F. (1981a), «Manescals, albeiters i ferradors de Mataró i el Maresme al segle XVIII», Anales del Colegio Oficial de Veterinarios de Barcelona, 38, 21-31. Los casos de interrupción del contrato por mala conducta del experto no son extraños en la documentación. Así, a pesar de la queja del albéitar de Benissanet, Josep Antoni Font, por la creación de una conducta con otro albéitar, la Real Audiencia confirmó la acción de los regidores y desestimó la protesta al comprobar que el mencionado albéitar «tiene su genio propenso a riñas y 
Conflictividad local y discrecionalidad administrativa fueron características que definieron las conductas a lo largo del siglo XVIII. La conflictividad de los ayuntamientos borbónicos en materia de reproducción de los grupos dominantes, de competencias jurisdiccionales o de venta de los cargos municipales también se manifestó en el momento de aprobar o revocar las conductas de común. Algunas de las denuncias presentadas ante la Real Audiencia por parte de vecinos, de albéitares o de las mismas autoridades locales muestran la utilización del argumento de la mala práctica como pretexto para renovar o liquidar conductas según conviniese ${ }^{15}$. El control ejercido por la Real Audiencia en esta materia no era sino aparente, provocando el desarrollo de una administración irregular en el tiempo y discrecional en la aplicación de medidas. La arbitrariedad política dificulta así la caracterización de las conductas de albéitar de común ${ }^{16}$. De este modo, la idea de la conducta abierta en una población donde había más de un albéitar tan sólo adquiría validez a discreción de las autoridades del Principado. Resulta complicado, por tanto, razonar los criterios seguidos por la Real Audiencia a la hora de decidir la re-

pendencias, de forma que por su mal modo ha sido puesto en la cárcel algunas veces por la Justicia de dicho Pueblo». ACA, RA, Consultas, reg. 475, 83r-84r, Barcelona, 8/3/1754.

15 En Montblanc, hallamos un ejemplo típico del intento de aprobar una conducta por parte de los regidores sin el consentimiento de los vecinos. La Real Audiencia intervino a partir de la protesta vecinal y ordenó la suspensión inmediata de la conducta. Algo parecido ocurrió en La Espluga de Francolí, donde los regidores intentaron forzar el pago de una nueva conducta de albéitar cuando los vecinos ya se hallaban satisfechos con el albéitar que tenían contratado desde hacía más de veinte años. No es infrecuente hallar, por otra parte, casos de suspensión de conductas, como la ejercida contra el albéitar de Vilalba dels Arcs, Joan Macip, «por no cumplir a la obligación de su conducta, faltando en acudir a las casas de los particulares que le llaman, de que se ha seguido morirse varios animales, sin curarse». ACA, RA, Consultas, reg. 156, 35rv, Barcelona, 11/7/1735 i 98rv, Barcelona, 26/8/1735; reg. 157, 19v20r, Barcelona, 30/1/1736.

16 La casuística es abundante en la documentación. A título de ejemplo, en el año de 1753 la Real Audiencia ordenó dejar la conducta abierta en la villa de Horta de Sant Joan ante las quejas del albéitar Josep Albacar, quien gozaba de la conducta en dicha villa desde hacía once años, por hallarse allí dos albéitares establecidos. Albacar protestó en 1756 que los regidores habían desobedecido aquellas órdenes. La Audiencia, sin embargo, no sólo permitió mantener vigente la conducta a pesar de haber ordenado anteriormente lo contrario, sino que fomentó el ejercicio libre de Albacar en la villa a pesar de la conducta. La renovación de la conducta provocó nuevas protestas de Albacar en 1763, pero la Audiencia las desestimó al considerar que una vez hecho el pago de la conducta, los vecinos eran libres de llamar al albéitar que les conviniese. ACA, RA, Consultas, reg. 474, 451rv, Barcelona, 9/11/1753; reg. 477, 589v, Barcelona, 2/12/1756; reg. 803, 283v-284v, Barcelona, 23/6/1763. 
novación o supresión de conductas, la obligación al pago de la conducta por todos los vecinos de la población o el decreto de concesión de libertad de llamar al albéitar que cada vecino considerase oportuno ${ }^{17}$.

Más allá de las obligaciones contractuales, los albéitares desarrollaron a lo largo del siglo XVIII su papel como expertos, poseedores de unos conocimientos que los avalaba ante las autoridades y que les permitían generar confianza. Esto consolidaba un fenómeno socioprofesional que se remontaba a los siglos medievales. Las autoridades solicitaron la presencia de albéitares para diferentes menesteres. Un caso frecuente de requerimiento, por ejemplo, estaba relacionado con la supervisión y examen del estado de salud de los animales antes de ser sacrificados por los tablajeros. De esta forma, al tiempo que se reconocía la experiencia del albéitar ante las enfermedades de los animales, quedaban señalados los límites de su práctica a los animales vivos. Hallamos, en este sentido, la presencia de albéitares por orden de las autoridades para el reconocimiento de los animales en las transacciones de compra y venta efectuadas por los prohombres del gremio de corredores de animales; también en el momento de examinar a los animales que iban al matadero en momentos críticos de presencia o sospecha de existencia de enfermedades contagiosas; y también en las comisiones facultativas que eran enviadas a la frontera con Francia para averiguar e informar sobre las señales, los síntomas y la calidad de las enfermedades que afectaban o podía sufrir el ganado de importación ${ }^{18}$.

17 En otro caso, tras ocho años con una conducta de común, el albéitar de Aitona, Jaume Falibert, protestó por la forma en que habían revocado su conducta: los regidores, se afirmaba, «movidos de su antojo se valieron de la estratagema tan intempestiva como precipitada que desde las nueve horas de la noche hasta las tres de la madrugada fueron de casa en casa llamando a los vecinos y diciéndoles si tendrían a bien lo que ellos harian en punto de conducir sirvientes, a lo que, como sorprendidos de improviso y pensando que rebajarían el salario de los dichos sirvientes, convinieron los vecinos». Falibert solicitó por ello la suspensión de la conducta del otro albéitar. La Audiencia, sin embargo, ordenó mantener vigente la nueva conducta hasta su extinción y concedió libertad a los vecinos, tras el pago de la conducta, para elegir al albéitar que mejor les pareciese. ACA, RA, Consultas, reg. 806, 304v-305v, Barcelona, 21/7/1776.

18 El albéitar como experto fue solicitado por la Audiencia, que aconsejaba a los corredores de animales hacerse con los servicios, «de peritos y albéitares para el reconocimiento correspondiente a su oficio»; el albéitar de Girona, Antoni Mota, pasó a inspeccionar en diversas ocasiones, a requerimiento del corregidor, si los animales que se mataban en el matadero padecían o no una enfermedad epidémica. ACA, RA, Consultas, reg. 469, 110v-111v, Barcelona, 13/3/1750 i reg. 158, 124v-125v, Barcelona, 24/12/1736. En la obrita del albéitar valenciano Salvador Montó Roca, Sanidad del Cavallo y otros animales sujetos al arte de albeytería, ilustrada con 
Sin embargo, el animal muerto o el examen de la carne del ganado desollado destinada para al abasto público no constituyeron una competencia del albéitar. Un hecho que también vendría confirmado por el parecer de las autoridades. Esto podría estar más relacionado con un conocimiento deficiente de la medicina interna de los animales que con la especialización del albéitar, de manera exclusiva según afirma Dualde, en la patología del ganado mayor y de pata hendida. Parece importante señalar así la ausencia del albéitar en la revisión de las porciones de carne de carnero, de vaca o de cerdo de los animales desollados, una vez conducidos a Barcelona en tiempos libres de la amenaza de enfermedades epizoóticas. Estas operaciones solían estar en manos de los prohombres del gremio de tablajeros, de los médicos encargados de experimentar con la carne de los animales desollados y de los revisores de las carnes que trabajaban a las órdenes del regidor-director del matadero de Barcelona. El revisor de las carnes era un oficial a las órdenes del ayuntamiento de la ciudad y, de manera parecida a las competencias y atribuciones que gozaba el mustassaf, la documentación no permite observar que se tratase de un oficio bajo el control de los albéitares barceloneses. El albéitar como experto tan sólo aparece cuando era solicitado por las autoridades para inspeccionar la carne de bueyes y vacas destinada al abasto público de la ciudad en tiempos de crisis epizoóticas ${ }^{19}$.

el arte de herrar, (València, Joseph Estevan Dolz, 1742, edición facsímil en Llibreries ParisValència), el tratado segundo destaca el ámbito de conocimiento del albéitar, manifestando el estudio de las enfermedades y de los vicios encubiertos. El texto también incorpora una advertencia a los albéitares sobre valoraciones de caballerías, en p. 221-222.

19 Ante el contagio de viruelas que sufría el ganado de lana en Tárrega, la Audiencia ordenó, entre otras medidas, la observación del progreso de las enfermedades, «haciéndose algún experimento en las Cabezas de Ganado que mueran, con asistencia del Regidor Revisor de Carnes, del Procurador Síndico General, del Experto nombrado por el Ayuntamiento y de un Médico, para venirse en conocimiento del mal». ACA, RA, Consultas, reg. 804, 573r-574v, Barcelona, 15/11/1764. Las enfermedades que padeció el vacuno que pastaba en la frontera con Francia, así como las sufridas por los rebaños del obispado de Girona fueron una preocupación constante para la Audiencia entre los años 1774 y 1776 y 1783. Información detallada sobre las medidas tomadas, la intervención de médicos, albéitares y otros expertos y la creación de comisiones de estudio se puede hallar en: Arxiu Històric de la Ciutat de Barcelona, Fons de Sanitat, Informes y Representaciones, vol. VI, reg. 12, 161r-269r (documentación intercalada), Barcelona, 1774-1776; reg. 14, 278r-488r (documentación intercalada), Barcelona, 1783; reg. 15, 61r66r, 240v-242r, 330v-333v y 389r-390v, Barcelona 1783. Sobre las inspecciones de la carne, véase: ZARzoso, A. (1994), Prevenció epidèmica i salut pública a la Barcelona del segle XVIII, Barcelona, Institut Universitari d'Història Jaume Vicens i Vives, Universitat Pompeu Fabra, 9699. Sobre el caso valenciano, véase: DUALDE (1995), La carne: su abastecimiento y control 
A pesar de la preceptiva solicitud de conducta que los municipios debían hacer ante la Real Audiencia, la documentación del siglo XVIII no resulta suficiente para establecer un mapa de la presencia y la distribución geográfica de albéitares en Cataluña. Convendría, en cualquier caso, no limitar la presencia de albéitares a las áreas de predominio de la ganadería ni a las localidades que mantenían destacamentos militares, que albergaban ferias de animales o que eran cruzadas por caminos carreteros y de herradura. A lo largo del siglo XVIII, la documentación muestra noticias de albéitares a lo largo y ancho de Cataluña, ejerciendo en poblaciones muy diversas. Además, parece importante no descuidar el fenómeno de la presencia de herreros en las villas y lugares, ya que su formación y su práctica los situaba en una posición próxima a los conocimientos de la albeitería de los animales.

Las diferencias entre el albéitar y el herrero han sido puestas de manifiesto con rotundidad. No cabe duda que el oficio del albéitar gozaba de un prestigio, proporcionado por unos conocimientos que lo diferenciaban del herrero. Estos aspectos eran evidentes en aquella sociedad, que premiaba al albéitar con un mayor prestigio social. A diferencia del herrero, el albéitar contratado por el común podía gozar de ciertas prerrogativas, como la exención de aquellas cargas concejiles - por ejemplo, el préstamo ordinario de caballerías para el tránsito de tropas- que podían impedir el desarrollo normal de su oficio. El goce de esta posición social inmediatamente superior a la del herrero también se fundamentaba en una mayor contribución económica, que se ponía de manifiesto tanto en los gastos de formación como en el pago de una tasa dos veces superior para la obtención del título de maestro albéitar: un pago que variaba entre las 19 libras 12 sueldos y las 22 libras 8 sueldos. Tal condicionante económico puede haber encubierto la práctica de la albeitería en el oficio del herrero y, por lo tanto, haber facilitado el acceso a determinadas prácticas médicas a estratos más modestos de la sociedad. De hecho, la convivencia gremial de albéitares y herreros en diversas ciudades y villas catalanas puede ayudar a comprender la complementariedad de la formación y de los conocimientos de albéitares y herreros. Otros factores, también económicos - el hecho de poder establecerse con mayor facilidad en las poblaciones o de estar menos gravados que los albéitares - , pueden justificar la mayor presencia de herreros en Cataluña y, por tanto, la existencia y difusión de otros recursos al alcance de la población ante la enfermedad animal ${ }^{20}$.

\footnotetext{
higiénico-sanitario en la Valencia foral, Madrid, Real Academia de Ciencias Veterinarias (discurso de recepción como académico electo) y (1997), 369-375.

20 Sobre las exenciones que gozaban los albéitares, véase: ACA, RA, Consultas, reg. 804, 340r-341v, Barcelona, 20/7/1764 (sobre cargas del servicio ordinario ajenas al oficio o a
} 
Más allá de los oficios regulados que se podrían encajar en la esfera médica, oficial, no resulta fácil establecer con evidencias documentales la existencia de otros recursos disponibles ante la enfermedad animal. Dejando aparte el recurso inmediato al consejo familiar o de las amistades, así como la figura mágica del pastor conocedor del rebaño y de sus enfermedades, las esferas religiosa y popular mostraron otros recursos disponibles al alcance de la población $\mathrm{y}$, por tanto, en competición directa con los ofrecidos desde la esfera médica.

El recurso a la protección divina muestra el engarce de las tres esferas, así como actitudes de represión y permisividad por parte de las autoridades ante el recurso popular a elementos rituales de la iglesia. A pesar del apoyo de la iglesia a la medicina universitaria, cuyos presupuestos teóricos también se hallaban presentes en la albeitería, la creencia en la causa sobrenatural de la enfermedad epidémica, tanto humana como animal, entendida como castigo divino, permitió la irrupción de un conjunto de rituales y remedios religiosos en el complejo y plural mundo de los recursos médicos disponibles. A ello cabe añadir que la apropiación y reelaboración popular de algunos de aquellos elementos aportó una variedad y una conflictividad mayor en las relaciones de las tres esferas teóricas aquí mencionadas. La religiosidad popular se manifestó así a partir de la devoción y creencia en la capacidad protectora o curativa de determinados santos oficiales o bien en la apropiación de signos rituales de la iglesia. En este contexto hay que situar el conocido caso de San Antonio Abad y su supuesta influencia protectora con los animales. La colaboración entre las autoridades locales, los propietarios de animales y el clero se puso de manifiesto en la organización de procesiones y misas dedicadas al santo patrón de los animales con el fin de rogar su protección ante la enfermedad epidémica y de representar la cohesión y el mantenimiento del orden social ante aquellas desgracias que sacudían los intereses generales de la población. Esta intercesión, sin embargo, no siempre estaba mediatizada por la iglesia. Por ello, la apropiación y reelaboración popular de los signos rituales religiosos para la protección o curación de los animales se convirtió en un

su ejercicio) y reg. 1.160, 175rv, Barcelona, 2/10/1797 (sobre exenciones fiscales). A diferencia de los gastos ocasionados por la expedición de títulos de albéitar y de herrero, el gasto originado por la visita de inspección del protoalbéitar fue la misma para ambos oficios y se mantuvo invariable a lo largo del siglo. Véase: ACA, RA, Consultas, reg. 147, 159v-160r, Barcelona, 28/5/1731 y reg. 1.159, 95v-99r, Barcelona, 14/8/1794. Resulta difícil mostrar con documentos la proporción de albéitares y herreros a partir de los números totales de las visitas registradas en el siglo XVIII. Un intento parcial, en el que se aprecia la mayor presencia de herreros en las poblaciones del corregimiento de Mataró, se halla en: LLEONART (1981a). 
fenómeno estrechamente vigilado por la iglesia. ${ }^{21}$ En otras situaciones no eran los propietarios de los animales sino los campesinos quienes recurrían a remedios milagrosos, cuyo poder salutífero era reconocido por la misma iglesia. Tal fue el caso de los labradores de El Vendrell, que consiguieron el permiso de las autoridades para viajar al santuario de Salarda, cerca de Estella, para obtener el «remedio singular [de] la milagrosa agua que llaman de San Gregorio [Ostiense]», con el que pretendían eliminar la plaga de procesionaria que amenazaba sus cosechas ${ }^{22}$.

La interposición y competición de los elementos característicos de las tres esferas también resulta evidente en el reconocimiento popular de aquellas personas consideradas dotadas de forma excepcional para la curación de los animales. La existencia de estos individuos fue manifestada por el protoalbéitar de Cataluña al considerar que su ejercicio se oponía a la práctica regulada de la albeitería, con la que aquella práctica heterodoxa competía por determinados espacios de control de la medicina animal. Las autoridades actuaron de forma arbitraria y pragmática ante este tipo de casos y sus decisiones no se alinearon de manera necesaria ni con el supuesto racionalismo administrativo del siglo XVIII ni con el apoyo a las atribuciones y competencias del protoalbéitar en su lucha contra el intrusismo. La actividad reguladora del protoalbéitar se vio obstaculizada por determinadas decisiones de la Real Audiencia que permitían, a la vista de su funcionamiento, el mantenimiento de prácticas opuestas radical-

21 La relación entre las esferas popular y religiosa necesita más estudios. Algunos ejemplos se pueden hallar en: GELABERTó, M. (1996), «Religión, enfermedad y medicina popular en la Cataluña del siglo XVIII», Historia Social, 26, 3-18; CAMPS, M. \& CAMPS, M. (1981), Santuaris lleidatans amb tradició mèdica, Lleida, Seminari Pere Mata-UB; MARTí, J. (1989), «Medicina popular religiosa a través dels goigs», Arxiu d'Etnografia de Catalunya, 7, 171-203 y (1992), La medicina popular catalana, Barcelona, Labor; RIBAS PONTí, F. (1994), Els goigs de l'Hospital General de Santa Creu de Barcelona, Barcelona, Seminari Pere Mata-UB. Sobre la procesión y exhibición de la imagen de San Antonio, organizada por las cofradías de San Antonio y San Aloy en Mataró, «con el fin de bendecir el ganado y preservarle del contagio por medio de la intercesión del santo», vegeu: ACA, RA. Consultas, reg. 151, 15v-16v, Barcelona, 1/7/1732 y 51r-52v, Barcelona, 4/8/1732.

22 La petición del síndico de El Vendrell fue bien acogida, «con condición de que al volver hayan de traer testimonio del cura o párroco del territorio donde se halla dicha agua, de haberla tomado de dicho paraje». En: ACA, RA, Consultas, reg. 154, 214rv, Barcelona, 20/4/1734. La devoción campesina a San Gregorio de Ostia, derivada de su capacidad benefactora en la preservación y lucha contra las plagas de langosta, se extendió a muchas poblaciones en los siglos XVII y XVIII. Un análisis de este fenómeno a partir del caso valenciano se halla en: Alberola, A. (1999), Catástrofe, economía y acción política en la Valencia del siglo XVIII, València, IVEI, p. 225-235. 
mente al ejercicio oficial de la albeitería. Este fue el caso, por ejemplo, de Víctor Taulats, «pobre labrador» de Llerona, quien, en su defensa ante las acusaciones de intrusismo manifestadas por el protoalbéitar, alegó «que tiene algún conocimiento natural de las dolencias de que enferman los bueyes, tocinos y otros animales, para cuyas curaciones es y ha sido llamado distintas veces de labradores amigos suyos y de otros que han tenido sus ganados enfermos y los ha curado sin percibir paga alguna» ${ }^{23}$.

Este ejemplo permite hablar de la existencia de dos elementos comunes a los tres ámbitos — popular, médico y religioso - de recursos disponibles ante la enfermedad. Se trata de la experiencia y la práctica cotidiana, de una parte, y la extensión, apropiación y reelaboración de las explicaciones humoralistas y religiosas de la enfermedad, de otra. El apoyo de las autoridades y la supervisión de la práctica de la albeitería, desde la Baja Edad Media, estaban directamente relacionados con la consolidación de la medicina universitaria. El ejercicio y el contenido teórico de los tratados de albeitería compartían los presupuestos teóricos de la doctrina médica vigente, el galenismo, así como los de la filosofía natural aristotélica que lo enmarcaba. Esto abrió las puertas a la transgresión de competencias entre la medicina humana y animal, tanto por parte de médicos como de albéitares, en disputa por el control de los espacios de la salud ${ }^{24}$.

En la Cataluña del siglo XVIII, el teniente de protomédico, centinela de las prácticas médicas, denunció la transgresión de competencias que se producía entre médicos, cirujanos y boticarios, haciendo saber a sus superiores que «Albéitares, mujeres, rústicos y otros se introducen en la Medicina, Cirugía, y Boticaria causando graves daños y desgracias». Esta intersección no sólo se dio en relación a las competencias de la esfera médica en la medicina humana, sino también a otras opciones posibles ante la enfermedad animal. Ello se producía sobre todo en función del papel clave que tenía la experien-

23 Un caso parecido fue el de Joan Taxà, tejedor de lana de Sabadell, que fue denunciado por el protoalbéitar por ejercer la albeitería, «porque ignora todos los principios del Arte y no sabe de [sic] leer ni escrivir para aprenderlos», y por haber osado dirigirse a la Audiencia, «manifestando algunas curaciones que casualmente habrá acertado y pidiendo permiso para ejercer la Albeitería». ACA, RA, Consultas, reg. 799, 46r-47r, Barcelona, 1/2/1760 y reg. 806, 98v-99v, Barcelona, 13/3/1766.

24 La identidad de presupuestos de la medicina humana y la medicina animal ha sido señalada en diversos trabajos. Véase: DuALDE (1997); CifuENTES (1999); CURTH (2003); CIFUENTES, L. \& FerRagud, C. (1999), «El Libre de la menescalia de Manuel Dies: De espejo de caballeros a manual de albéitares», Asclepio, 51, 93-127; LLEONART, F. (1974a), «Evolución científica de la veterinaria española en los siglos XVII y XVIII», Terapéutica Veterinaria Biohorm, 23, 39-60. 
cia práctica o, tal y como argumentó Víctor Taulats, el «conocimiento natural» de las enfermedades de los animales ${ }^{25}$.

Más arriba se ha destacado el fenómeno de la apropiación y adaptación popular de los rituales religiosos ante la enfermedad tanto en la medicina humana como en la animal. Desde el ámbito de la experiencia práctica cotidiana, el cuerpo doctrinal de la albeitería y la farmacia galénica fueron asumidos y adaptados por la práctica popular ante el fenómeno de la enfermedad animal. Los escasos estudios existentes sobre los contenidos de los tratados de albeitería durante el período moderno han mostrado aspectos muy significativos con relación al escaso desarrollo y a la ausencia de comunicación o recepción de las doctrinas de la medicina humana.

Por una parte, se ha señalado la concentración casi exclusiva en el conocimiento del ganado de pata hendida y en especial del caballo. Sanz Egaña y Dualde sólo han apuntado los trabajos de tres albéitares-Álvarez Borges (1680), Royo (1734) y Álvarez Calderón (1786?) — que dedicaron algunas páginas a la patología bovina y que, según el parecer de estos estudiosos, ni siquiera merecerían mención ya que nada aportan. Por otra parte, se ha afirmado que el conocimiento de la anatomía externa del caballo mejoró, si bien se mantuvo en un nivel muy descriptivo y superficial, y se benefició de los conocimientos médicos de la anatomía humana. En contraste, la anatomía interna y las disecciones experimentales tan sólo hallaron eco en los tratados de unos pocos albéitares - García Conde (1685), Sánchez Lago (1717) y García Cabero (1748) - y lo mismo se puede afirmar de los estudios fisiológicos de los animales — de la Reyna (1564). La semiología de las patologías, el conocimiento de los signos de las enfermedades, halló un camino de dificultades en su acceso a los tratados de albeitería, a menudo basados en el conocimiento empírico de las enfermedades a partir de diagnósticos clínicos preestablecidos mediante la inspección y palpación externas, y en la designación de tratamientos terapéuticos generales ${ }^{26}$.

25 El memorial de denuncia del protomédico se halla en: ACA, RA, Consultas, reg. 145, 52v54r, Barcelona 12/5/1730. Una síntesis del tema de la transgresión de las competencias médica se puede ver en: LINDEMANN, M. (1996), Health and healing in eighteenth-century Germany, Baltimore, Johns Hopkins UP, p. 22-71. La transgresión de estas competencias desde el punto de vista de la albeitería, junto a la política arbitraria de las autoridades borbónicas en esta materia tiene un ejemplo singular en el caso del albéitar-cirujano Vergés. Véase: LLEONART, F. (1974b), «Joseph Thomas Vergés, insigne Albeytar ilerdense promovido a Cirujano en 1754 por aclamación popular», Terapéutica Veterinaria Biohorm, 24, 114-121 y (1988), «Joseph Thomas Vergés, Albeiter de Lleida i la seva activitat com a cirurgià», Gimbernat, IX-I, 171-177.

26 Sobre esta cuestión, véase: SANZ EGAÑA, C. (1941), Historia de la Veterinaria española. Albeitería, mariscalería, veterinaria, Madrid, Espasa Calpe y (1955) «Diego Álvarez Calderón de 
El empirismo pragmático y poco especulativo de los albéitares se hizo muy evidente en el caso de la epizootia manifestada en el Valle de Arán en 1731. Ante los problemas que la enfermedad podía causar, tanto económicos como de amenaza para la salud humana, las autoridades pidieron el consejo experto de médicos y albéitares con el fin de conocer la calidad de las enfermedades y el tipo de precauciones que se debía adoptar. El informe de los albéitares se caracterizó por ser una mera descripción elemental basada en la casuística humoralista y en el énfasis dado al aire, entendido como el más importante de las seis cosas no naturales. En contraste, el informe de los médicos se apoyó en las autoridades médicas más importante en la materia, mostrando el conocimiento de la literatura médica coetánea relacionada con las enfermedades animales. En los trabajos de Bernardino Ramazzini y de Giovanni Lancisi se consideraban las posibles causas de las enfermedades epizoóticas que habían afectado diversas áreas de Europa desde finales del siglo XVII. Los autores de estos textos aconsejaban a las autoridades diversas medidas para prevenir el progreso de la enfermedad, entre las cuales incluían las «inspecciones Anathómicas» de los animales ${ }^{27}$.

la Barca, Protoalbéitar de Cataluña», Anales del Colegio Oficial de Veterinarios de Barcelona, 12 , 383-88; DUALDE (1997), p. 227-344; LLEONART, F. (1981b), «El saber anatómico de los albeytares españoles», Terapéutica Veterinaria Biohorm, 20, 45-53 y (1973), «El diagnóstico clínico en la Albeytería española», Terapéutica Veterinaria Biohorm, 21, 51-59. En cuanto al signo de interrogación que aparece tras la fecha del tratado de Álvarez Calderón, véase la nota 39.

27 Los médicos que firmaron el informe fueron el teniente de protomédico Francesc Clarassó y los doctores del último claustro de la facultad de medicina de Barcelona, antes de la supresión de 1717: Rafael Esteve, Josep Fornés, Joan Pla y Geroni Badia. La existencia de los libros mencionados consta en la biblioteca particular de Rafael Esteve, véase: ZARZOSO, A. (2004), Medicina i Il-lustració a Catalunya. La formació de l'Acadèmia Mèdico-Pràctica de Barcelona, Barcelona-Lleida, Fundació Noguera-Pagès Editors. En cuanto a los dos informes médicos, véase: LleONART, F. (1978), «La epidemia del ganado en el Valle de Arán en 1731», Terapéutica Veterinaria Biohorm, 43, 141-149. No deja de sorprender la comparación que hace este autor al calificar el informe de los médicos como «un estudio tan complejo como pedantesco y que no hace más que divagar». Véase también: JORDI, R. (1980), «Precauciones para proteger al ganado de España de una epidemia registrada en Francia. Año 1732», Terapéutica Veterinaria Biohorm, 49, 38-44. Sobre el carácter de la enfermedad epidémica, las medidas adoptadas por las autoridades y los trabajos médicos sobre la calidad de las enfermedades, véanse: MCCloy, S. T. (1946), Government Assistance in Eighteenth-Century France, Durham, Duke UP, 106-134; HuYGELEN, C. (1997), "The immunization of cattle against rinderpest in eighteenth-century Europe», Medical History, 41, 182-196; CRAVOT, C. (1999), La participation d'un academicien, F. Vicq d'Azyr, à la resolution de l'epizootie de 1774, Tesis inédita, Facultad de Medicina de Nantes, 16-20 y 58-133. 
El objetivo perseguido al mostrar esta caracterización superficial de los conocimientos de la albeitería de la época moderna es señalar la importancia del empirismo y la experiencia de la práctica cotidiana como denominador común de las prácticas médicas y como catalizador de la apropiación popular del discurso médico y de la materia terapéutica, basados en la doctrina galénica humoral. En este sentido, la existencia de un conjunto de recursos terapéuticos tradicionales concedió la iniciativa, en materia médica, a los mismos interesados, sin experimentar la necesidad de recurrir a expertos. Este hecho, fundamental en la realidad de una experiencia práctica compartida, permitió a los interesados decidir el recurso médico más conveniente según el carácter de la enfermedad. Esta idea necesita mayores apoyos y esto requeriría estudios centrados en la perspectiva de las culturas médicas. Un ejemplo podría venir del análisis del ya mencionado Libro del Prior, que ejerció un papel de bisagra en la difusión y popularización de las ideas médicas universitarias.

En efecto el libro escrito por el clérigo Miquel Agustí gozó de un éxito impresionante: publicado en 1617 en catalán en Barcelona y editado en castellano al menos una veintena de veces entre 1626 y 1785 (en Perpiñán, Zaragoza, Madrid y Barcelona). El libro no sólo es un manual de técnica agrícola para labradores, también es un manual de medicina doméstica humana y animal ${ }^{28}$. Las páginas dedicadas por Agustí a los remedios de las enfermedades humanas y a las curas de las enfermedades animales demuestra de nuevo la intersección de las tres esferas - religiosa, médica y popular. Se trata, por tanto, de la lectura hecho por un representante de la iglesia de la medicina universitaria $\mathrm{y}$, a la vez, de su adaptación y popularización destinada a una audiencia no experta que procedería, tras su lectura o transmisión, a interpretarla y ajustarla a sus necesidades ${ }^{29}$. Esta popularización de la medicina universitaria resulta excepcional tratándose de una materia como la medicina animal. Por una parte, el libro de Miquel Agustí adapta un hecho fundamental que hallamos en los tratados de albeitería: el despacho inmediato del tratamiento para cada una de las enfermedades más comunes y características de los animales. Por otra, el manual supera los límites de los tratados de albeitería dedicados a los caballos, dando cuenta también de los remedios y las curas

28 Sobre el Libro del Prior, véase la nota 9. Conviene remitir a los estudios introductorios que aparecen en la edición citada, en especial las páginas escritas por Lluís Argemí.

29 Al considerar el objetivo del texto y su perdurabilidad, se ha señalado que la obra «representava un autèntic Vademecum per aquells que havien d'aconsellar al poble». Véase: SABAtÉ, J. M. \& SABAtÉ, J. (2002), Un manual casolà de medicina. «El llibre del Prior», Manresa, PAHCS, p. 16. 
de todos los animales domésticos ${ }^{30}$. Necesitamos, por tanto, un análisis serio de los contenidos de libros como el citado y también de su consumo, de su presencia en las bibliotecas particulares, de la identidad de sus poseedores, ya que éstos tenían en sus manos la posibilidad de tomar la iniciativa y el control ante la enfermedad animal a partir de unos conocimientos asequibles, extractados del galenismo y susceptibles de ser reelaborados.

\section{EL CAMINO HACIA LA VETERINARIA}

Una vez señalado, si bien de manera superficial, el complejo entramado que caracterizó a la pluralidad de recursos disponibles ante la enfermedad animal, así como la intersección, adaptación y reelaboración de la doctrina médica y de ciertas prácticas religiosas en las tres esferas mencionadas conviene revisar los planteamientos presentistas que hallamos en determinados estudios históricos sobre la albeitería. Esto no tiene otro fin más que situar en su contexto histórico el significado de las innovaciones, típicamente borbónicas, introducidas en materia de albeitería a lo largo del siglo XVIII.

El afán reivindicativo de los historiadores de la veterinaria de un status científico de su profesión y de las bases científicas de la misma, sobre todo en comparación con el de los médicos, ha forzado una línea de interpretación que, a grandes rasgos, viene a considerar el siglo XVIII como un período de ocasiones perdidas para convertir la albeitería en la veterinaria científica, que se inició a partir de la creación de las escuelas de veterinaria europeas. En buena medida, esta visión ha participado del deslumbramiento que a otros historiadores de la ciencia les ha provocado el valor concedido a las medidas supuestamente modernizadoras que las autoridades borbónicas introdujeron en materia de «reestructuración y unificación de la sanidad española» ${ }^{31}$.

La interpretación histórica dominante en los estudios de la albeitería ha destacado la existencia de una auténtica «esclavitud gremial de la albeytería»

30 El libro no sólo comprende la albeitería o medicina de «los cavalls, [...], les eguas, y pollins, [...], lo bestiar mulatí, y altres besties de treball», también las de los «bous, vaques, y vadells, porchs y porcells, gallines y pollam, ocas, anechs, signes, y altres aucells de aygua, flaysants, pagos, galls y gallinas de las Indias, tortoras, perdius, gualles, y coloms salvatges, coloms domestichs, conills domestichs, ovelles, moltons y anyells, cabras, cans, abelles, cuques de filar seda».

31 Sobre esta cuestión, con relación al mundo de la farmacia, véase: ZARZOSO, A. (1996), «Protomedicato y boticarios en la Barcelona del siglo XVIII», Dynamis, 16, 151-171. 
como la causa principal del atraso científico de la albeitería. Desde esta perspectiva, la extensión de las atribuciones del tribunal del protoalbeyterato a los territorios de la Corona de Aragón a principios del siglo XVIII constituyó una oportunidad para elevar el rango de la albeitería, dado el supuesto mayor interés por parte de aquel tribunal por la actividad clínica. No obstante, el mantenimiento de los gremios y, por tanto, de sus competencias en materia de formación, organización y regulación del oficio supuso un obstáculo a los posibles cambios que se vislumbraban. Además, el proyecto de renovación sanitaria borbónico no cuajó en el ámbito de la albeitería debido al hecho que la escuela de veterinaria creada en Madrid en vez de encabezar tal proyecto no hizo sino contribuir a su decadencia al convivir con las instituciones tradicionales de la albeitería ${ }^{32}$. Parece que, en función de lo que se ha planteado en este trabajo, conviene hacer un análisis más matizado del supuesto proyecto borbónico de renovación sanitaria para poder valorar los resultados de la institucionalización del protoalbeyterato en los territorios de la Corona de Aragón y de la creación de una escuela de veterinaria.

El estudio de la documentación de la Real Audiencia permite adelantar que tras las transformaciones administrativas y legislativas introducidas por los Borbones hubo un predominio de los intereses políticos por encima de los estímulos profesionales. En efecto, conviene recordar que los decretos de Nueva Planta de 1718 no cuestionaron la vigencia, la forma de organización y las funciones y atribuciones de los gremios. Las medidas ejecutadas no fueron más allá de la supresión de su representación y participación política en el gobierno de la ciudad y, desde entonces, de su supeditación a las órdenes de la nueva Real Audiencia. Resulta evidente que la permanencia de los gremios era inseparable de la sociedad de antiguo régimen, a la que contribuía, entre otras cosas, mediante el mantenimiento del orden social. En este sentido, la confirmación por la autoridad real de los privilegios gremiales en los diversos ámbitos de la medicina tendría que ser considerada como un obstáculo a aquellas medidas que, pretendidamente, formaban parte del llamado proyecto

32 Para los aspectos principales de esta interpretación, véase: SANZ EGAÑA (1941); DuAlde (1997); Herrero Rojo, M. (1984), La albeytería española en el siglo XVIII, Salamanca, Gráficas Cervantes, 161-81 y 203-22; RUIBÉRRIZ, P. V. (1984), Historia de la ciencia veterinaria española: del Antiguo Régimen al Liberalismo, 1792-1847, Tesis doctoral editada, Madrid, Universidad Complutense, 14-40; Roca TORRAS, J. (1991), Historia de la Veterinaria en Cataluña (1400-1980), Tesis doctoral inédita, Barcelona, UAB, 6-30; LlEONART, F. (1979), "Cuatrocientos años de veterinaria en Cataluña (s. XIV-XVIII)", Terapéutica Veterinaria Biohorm, 46, 82-90. 
de renovación sanitaria borbónico. Y ello debido a que esta política sería opuesta a la re-creación de la figura del protoalbéitar en Cataluña y a su supuesta misión de organización y control de la albeitería. A la vista de la documentación conservada, principalmente en la Real Audiencia para el caso catalán, parece conveniente matizar esta línea interpretativa.

Tal y como sucedió con otros oficios, la reorganización administrativa posbélica se tradujo en Cataluña en una política de militarización de los cargos considerados estratégicos. Así, a pesar de la clara relación de la albeitería con el ejército, la concesión del oficio de protoalbéitar a Diego Álvarez en septiembre de 1717 confirmaba tal programa de control. De la misma manera que se abría un largo período de conflictos y pleitos en materia de competencias y jurisdicciones entre los boticarios, los cirujanos, los médicos y los protomédicos del Principado, el protoalbéitar Diego Álvarez tuvo que hacer frente a un buen número de pleitos planteados en contra de su actuación y de sus atribuciones por parte de los albéitares. Esto respondía a dos factores característicos de la administración borbónica: por una parte, la concentración del gobierno político en la Real Audiencia impidió dotar al protomédico y al protoalbéitar de reglamentos jurídicos bien definidos que permitiesen el desarrollo de sus atribuciones mediante la constitución de un tribunal. Por otra parte, la concesión de estos cargos como premio a fidelidades o servicios reales convirtió los oficios del protomédico y del protoalbéitar en meros recaudadores de unos ingresos notables que, según se desprende de la documentación consultada, no era necesario justificar ante otras instancias de gobierno ${ }^{33}$.

Hasta mediados del siglo XVIII, las actividades de los protoalbéitares Diego Álvarez, padre e hijo - el cargo aparece por vez primera como hereditario- se vieron obstaculizadas por los pleitos entablados por los gremios de herreros y albéitares de determinadas poblaciones catalanas, a partir de la defensa de unas ordinaciones gremiales confirmadas por las propias autoridades. La ausencia de un marco jurídico estable que apoyase la actividad del protoalbéitar motivó la expedición continuada de despachos dirigidos tanto a

33 Sobre la concesión del oficio de protoalbéitar a Diego Álvarez, véase: ACA, RA, Consultas, reg. 124, 72r-73r, Barcelona, 17/9/1717, donde la Audiencia informa de manera positiva los méritos militares de Álvarez. Cabe apuntar que los datos del informe de la Real Audiencia sobre el oficio del protoalbéitar en Cataluña han sido confundidos por algunos autores, ya que su redacción se ejecutó a partir de la solicitud presentada por Pedro Capdevila para optar a tal cargo. Véase: ACA, RA, Consultas, reg. 122, 43r-44r, Barcelona 31/3/1717 y LLEONART, F. (1974c), "Nuevas aportaciones a una historia de la veterinaria catalana en el siglo XVIII", Terapéutica Veterinaria Biohorm, 25, 164-72. 
las autoridades locales conminando a prestar asistencia al protoalbéitar como a los herreros y albéitares de todos los corregimientos del Principado, a excepción del de Barcelona, exigiendo obediencia al protoalbéitar ${ }^{34}$.

El desinterés de la autoridad en el control de las funciones del protoalbéitar también se puede observar en la regulación de la fiscalidad que se debía aplicar sobre los albéitares y herreros en concepto de visitas de inspección y de expedición de títulos. En los primeros intentos de realizar visitas anuales, entre los años 1720 y 1729, la Real Audiencia ordenó la tasa de 1 libra y 8 sueldos para cada albéitar y herrero visitado o inspeccionado. A partir de diciembre de 1729, el Consejo de Castilla impuso las visitas por cuatrienios y el cobro de 2 libras y 16 sueldos por cada albéitar y herrero visitado. La mayor parte de los datos fiscales que aparecen en la documentación están relacionados con la intervención que la Real Audiencia hizo en la visita del protoalbéitar a los corregimientos de Girona, Mataró, Tarragona y Vilafranca, a partir de 1749. Esta visita no la hizo directamente el protoalbéitar, sino que la realizó mediante delegación en otros albéitares. No deja de ser significativo que estas evidencias se manifiesten en la documentación de la Real Audiencia, no tanto por un interés de aquella administración en controlar la actividad y la recaudación del protoalbéitar como por el incumplimiento de éste - en esta ocasión, Diego Álvarez hijo- de las obligaciones testamentarias que tenía hacia su madre y sus hermanas ${ }^{35}$.

34 Sobre la conflictividad entre el protoalbéitar y los gremios de herreros y albéitares, véase: ACA, RA, Consultas, reg. 138, 160rv, Barcelona, 2/8/1726; reg. 147, 159v-160r, Barcelona, 28/5/1731; reg. 473, 461v-463r, Barcelona, 5/12/1752 y reg. 474, 28v-29v, Barcelona, 20/2/1753. Hallamos gremios de albéitares, herreros y otros trabajadores del metal en Barcelona, Mataró, Tarragona, Tortosa, Valls, Vic, Igualada, Lleida y Vilafranca del Penedès. Sobre la conflictividad entre el protoalbéitar y los gremios valencianos, véase: DUALDE (1997), p. 191.

35 ACA, RA, Consultas, reg. 138, 160rv, Barcelona, 2/8/1726 y reg. 144, 252v-253v, Barcelona, 1/12/1729. El protoalbéitar Diego Álvarez consiguió la aprobación para traspasar el cargo a su hijo Diego, una vez que le llegase la muerte. (ACA, RA, Consultas, reg. 157, 149r-151r, Barcelona, 4/6/1736.) Mientras el hijo acabó la formación como albéitar, el control de la albeitería catalana estuvo en manos de su madre, Josefa Calderón de la Barca, quien ejercía el cargo mediante albéitares interventores en cada corregimiento. (ACA, RA, Consultas, reg. 158, 215rv, Barcelona, 13/5/1737 y reg. 160, 102rv, Barcelona, 3/7/1738.) A partir de 1749, el protoalbéitar Diego Álvarez, hijo, comenzó a mostrar signos de irresponsabilidad hacia su madre y hermanas, faltando a la letra de las cláusulas testamentarias de su padre. Desde entonces, un buen conjunto de noticias aparecen en las consultas de la Real Audiencia, informando sobre las quejas de su madre, las protestas elevadas por albéitares y herreros, los fraudes y deudas del protoalbéitar y las intervenciones de otros albéitares - Pau Fargas, Jacint y Josep Oliver, Miquel Fontanet— nombrados por la autoridad para controlar el ejercicio de la 
Más allá de las causas de generación de esta documentación, los datos que contienen aportan nuevos elementos para el estudio. Por una parte, desde la década de 1760, se puede observar el mantenimiento de la misma tasa para las visitas, mientras que la expedición de títulos de herreros y de albéitares aumentó, oscilando entre las 9 libras y 16 sueldos/11 libras y 4 sueldos y las 19 libras y 12 sueldos $/ 22$ libras y 8 sueldos, en función de cada oficio. Ante el valor económico de estos títulos, cabe recordar la mayor presencia de herreros en las cuentas examinadas por Lleonart para el corregimiento de Mataró en los años 1760. Parece difícil generalizar esta imagen al resto de Cataluña, en buena medida a causa de la falta de estudios, pero la idea de una práctica de la albeitería bajo el título de herrero no se nos presenta como temeraria. Por otra parte, el producto total que aparece en alguna de las visitas efectuadas muestra claramente que el cargo de protoalbéitar no era sino un lucrativo negocio. En este sentido, la visita realizada a los doce corregimientos catalanes - el de Barcelona quedaba fuera de su competencia - en el cuatrienio de 1745-1748 comportó un producto total de 3.690 libras, más 400 libras de gastos creados por la propia visita. Sabemos que un tercio de las cerca de 824 libras recaudadas por el albéitar Pau Fargas en la intervención que hizo en nombre de la Real Audiencia en los cuatro corregimientos mencionados más arriba se convirtió en su salario libre de gastos, mientras que los otros dos tercios fueron a parar a las manos de la viuda Álvarez. El producto resultante de la visita realizada entre los años 1783 y 1785 a un total de 1.786 albéitares y herreros ascendió a la cantidad de 10.001 libras y 18 sueldos, produciendo un gasto general de visita de 840 libras. ${ }^{36}$ Debemos añadir que el carácter productivo del negocio del protoalbéitar resultaba demasiado eviden-

albeitería en los corregimientos mencionados. Véase, entre otros documentos: ACA, RA, Consultas, reg. 469, 133r-135v, Barcelona, 18/4/1750 y 344r-346r, Barcelona, 29/7/1750; reg. 471, 135v-137v, Barcelona, 22/4/1751; reg. 799, 285v-286v, Barcelona, 9/5/1760; reg. 801, 372r-373r, Barcelona, 3/8/1761; reg. 802, 204v-205v, Barcelona 18/5/1762 y 341rv, Barcelona, 8/9/1762; reg. 804, 299r-300r, Barcelona, 6/7/1764; reg. 805, 212v-215r, Barcelona, 23/5/1765; reg. 806, 33r-34r, Barcelona, 30/1/1766, 97rv, Barcelona, 13/3/1766 y 434v-436r, Barcelona, 10/10/1766 y reg. 808, 41v-42r, Barcelona, 20/2/1768.

36 Sobre la recaudación efectuada durante la visita del albéitar interventor Pau Fargas, véase: ACA, RA, Consultas, reg. 803, 307v-311v, Barcelona, 30/6/1763 y 636v-638r, Barcelona, 2/12/1763. Sobre las visitas efectuadas en los años 1780, véase: ACA, RA, Consultas, reg. 1.159, 124r-125r, Barcelona, 29/10/1794. Los 1.786 albéitares y herreros visitados se distribuían de la siguiente manera: 528 fueron visitados en 1783 en los corregimientos de Lleida, Tortosa, Puigcerdà, Talarn y Vall d'Aran, 392 lo fueron en 1784 en los de Manresa, Cervera y Vic, y 866 lo fueron en 1785 en los de Girona, Mataró, Tarragona y Vilafranca. 
te visto desde la perspectiva de la sociedad catalana coetánea. Esto se manifestó, por una parte, a partir del interés que mostraron determinados albéitares para hacerse cargo de las intervenciones ordenadas por la Real Audiencia, que como hemos visto generaron unos ingresos significativos para los albéitares-interventores. Las intervenciones se prolongaron entre los años 1750 y 1782. A partir del año 1763 y a causa de los numerosos fraudes cometidos y del aumento de las deudas del protoalbéitar Diego Álvarez, las autoridades añadieron el corregimiento de Lleida a los cuatro corregimientos hasta entonces visitados. Por otra parte, una vez muerto Diego Álvarez el año 1793, la particular nómina de pretendientes al cargo de protoalbéitar mostraba de nuevo la percepción que de este oficio tenía la sociedad: sólo dos de los ocho aspirantes eran albéitares. Un hecho que, a pesar de la concesión del cargo a un albéitar, se repitió en la nueva adjudicación que se hizo del oficio el año 1799 , cuando fueron tres de los siete pretendientes los que defendieron su condición de albéitares ${ }^{37}$.

El resultado de la actividad de los protoalbéitares e interventores que ejercieron el control de la albeitería en la Cataluña del siglo no puede ser más decepcionante. Tampoco contribuye a mejorar esta visión el análisis de la actividad científica desarrollada por aquellos individuos. Se ha señalado, tal vez en exceso, la importancia de las palabras contenidas en el despacho del título de albéitar, expedido por los protoalbéitares, sobre las futuras obligaciones del práctico: «se le manda al dicho [...] Maestro Albéitar tenga desde el día que se le da este despacho, todos los libros más precisos de Albeitería, como también el estuche completo, con todos los instrumentos precisos de su Arte». Parece necesario insistir, en función de esto, en la necesidad de ampliar nuestro conocimiento sobre este asunto a partir del estudio de inventarios postmortem de albéitares. Esta fuente, que suele incorporar las pertenencias del individuo en el momento de su muerte, nos permitiría evaluar y confirmar la realidad del mandato incluida en el título. En todo caso, la conclusión a la que ha llegado Lleonart tras analizar las firmas de los albéitares no incita grandes esperanzas sobre el carácter ilustrado de aquellos individuos. Como respaldo a la interpretación de Lleonart, no deja de ser significativo el hecho de hallar las siguientes palabras en el colofón de los títulos de albéitar y de herrero expedidos por Josep Oliver, uno de los albéitares-interventores nombrados por la Real Audiencia: «[...] por no saber escribir doy facultad a Mi-

37 LLEONART (1981a). En cuanto a los pretendientes al cargo de protoalbéitar del Principado de Cataluña, véase: ACA, RA, Consultas, reg. 1.159, 95v-99r, Barcelona, 14/8/1794 y reg. 1.162, 4r-5r, Barcelona, 7/1/1799 i 19v-24r, Barcelona, 6/3/1800. 
guel Sala estudiante, para que firme en mi nombre. Por Joseph Oliver Albeytar: Miguel Sala, estudiante». Esto vendría a confirmar una realidad muy concreta: menos científica y más preocupada por la recaudación de las tasas derivadas del control del ejercicio del albéitar y el herrero ${ }^{38}$.

El escaso número de trabajos relacionados con la albeitería y publicados durante nuestro período de estudio en Cataluña vendría a corroborar la imagen que acabamos de señalar. Por una parte, disponemos de dos tarifas publicadas, una por Diego Álvarez en 1784 y otra por Pau Fargas, posterior al año 1807. La redacción de tarifas de las actividades de los albéitares y herreros era una competencia del protoalbéitar comparable a la realizada por el protomédico sobre tarifación de los precios de las drogas simples y compuestas que debían manipular los boticarios o a la realizada por el Real Colegio de Cirugía de Barcelona sobre las operaciones propias de los cirujanos. La lectura fragmentaria de las tarifas escritas por los albéitares pone de manifiesto, por un lado, la identidad de presupuestos teóricos de la albeitería con la doctrina médica galénica y, por otro, el carácter práctico y externo de la clínica y de la terapéutica de la albeitería durante el período moderno.

Además de las tarifas, existe un tratado de albeitería firmado por el mismo Diego Álvarez, publicado en 1774. El tratado se centra de manera exclusiva en el arte del herrado. Escrito en el característico y práctico diálogo entre maestro y discípulo, el tratado de Álvarez no aporta nada desde el punto de vista teórico si comparamos con obras anteriores más completas, como por ejemplo la de Bartolomé Guerrero, publicada en 1686. A pesar de esto, el libro de Álvarez confirmaría la importancia que tenía el ganado de pata hendida en una coyuntura de intenso tráfico de mercancías en Cataluña. Además, una primera lectura comparada del tratado de Álvarez y del libro escrito por Salvador Montó en 1742 nos permite observar similitudes sospechosas. Si bien el tratado del protoalbéitar catalán en ningún momento llega a mostrar los detalles, la extensión y las ilustraciones que aparecen en el libro del albéitar valenciano ${ }^{39}$.

38 El primer comentario sobre la importancia de la letra del título mencionado lo hallamos en: SANZ EGAÑA (1955). Las citas proceden de: LLEONART (1979).

39 Sobre las tarifas, véanse: LlEONART, F. (1974d) «Aspectos económicos inéditos de la veterinaria española del siglo XVIII», Terapéutica Veterinaria Biohorm, 26, 232-43; LLEONART, F. (1974e), "Aspectos económicos inéditos de la veterinaria española del siglo XVIII», Terapéutica Veterinaria Biohorm, 27, 294-308; CuBERAS, N \& CUBERAS, A. (1991), "Tarifes dels medicaments i operacions de cirurgia humana i veterinària al segle XVIII i principis del XIX», Gimbernat, XV-I, 107-17. En cuanto a la fecha de la tarifa publicada por Fargas, podemos señalar su ausencia al frente de este cargo a la vista de la cronología de todos los pro- 
La ausencia de un verdadero proyecto de renovación sanitaria se puede observar de nuevo en el contexto de cambios que llevó a la creación de la Real Escuela de Veterinaria de Madrid en 1793. El Real Tribunal del Protoalbeyterato de la corte intentó, sin éxito, en 1791 poner fin a la conflictividad derivada del mantenimiento y confirmación de las prerrogativas gremiales. El medio propuesto por los Alcaldes Mayores y Examinadores de aquella institución consistía en suprimir las prerrogativas gremiales y en centralizar en el tribunal de la corte todas las competencias reguladoras de la albeitería, esto es, la inspección y la expedición de títulos ${ }^{40}$.

Cabe preguntarse, a la vista de tal propuesta, sobre el carácter de la solicitud del cargo de protoalbéitar de Cataluña planteada por Segimon Malats, primer director de la escuela de veterinaria de Madrid. ${ }^{41}$ No sabemos si esta operación podía constituir un intento de controlar las subdelegaciones del Real Tribunal del Protoalbeyterato como paso previo a la centralización y uniformización de la política reguladora de la albeitería. Si recordamos los términos de la reforma del Real Tribunal del Protomedicato y de sus subdelegaciones en la década de 1760, tal vez la operación podía constituir un intento de asegurar la entrada en las arcas del tribunal central de los ingresos procedentes de las inspecciones y las titulaciones. Aún parece más complicado dar una respuesta segura si atendemos al desinterés mostrado por las autoridades borbónicas en el establecimiento de un nuevo modelo de control y fomento de

toalbéitares catalanes hasta el año 1807. Además, en la tarifa de Fargas aparece una mención al rey Fernando VII. Sobre el tratado de albeitería citado, he consultado el ejemplar de la Biblioteca de Cataluña: Diego Álvarez Calderón de la Barca, Tratado de herrar caballos y demas animales sugetos a la beterinaria facultad, condusibles al humano servicio, en diálogo compuesto y disputado entre maestro y discípulo, sacado de doctrinas de varios prácticos que da a luz don... (Girona, Joseph Bró, s.a., "imprímasse 2 de agosto de 1774»). Se ha señalado la existencia de un segundo ejemplar del tratado de Álvarez, fechado en 1786, y que incluye además un trabajo sobre enfermedades del ganado bovino y un edicto contra la rabia. Tan sólo he podido detectar, sin llegar a su consulta, la existencia de una copia de este segundo tratado en la Biblioteca Histórica Municipal de Madrid. La asignación de la fecha de 1786 parece estar más relacionada con el mencionado edicto contra la rabia decretado por el Conde del Asalto en 1786. Sobre este edicto y su reproducción, véase: LLEONART, F. (1991), «Aspectos históricos en el conocimiento de la rabia», Terapéutica Veterinaria Biohorm, 6, 55-59. Para otros tratados de albeitería anteriores, véase: LlEONART (1981b). Sobre el tratado de Montó, véase la nota 18.

40 Sobre el proyecto del tribunal central, véase: DUALDE (1997), p. 192.

41 La denegación consignada a la petición de Malats se halla en: ACA, RA, Consultas, reg. 1158, 61v-62r, Barcelona, 16/4/1791. Sobre Malats, véase: SeCULi BRILLAS, J. (1995), «Mariscals, Manescals, Veterinaris. Segimon Malats», Gimbernat, XXIV-II, 237-244. 
la enseñanza y el ejercicio de la albeitería. Cabe recordar, además, que la creación de la escuela de veterinaria de Madrid en 1793 coincidió con la reiteración, también infructuosa, de la petición de 1791 realizada por el Real Tribunal del Protoalbeyterato.

La actitud de la Real Audiencia de Cataluña ante la nueva ofensiva del Real Tribunal del Protoalbeyterato constituye una muestra más de la dificultad de creer en la existencia de un verdadero proyecto de renovación sanitaria en manos de los Borbones. La Real Audiencia apostó para que «no se haga novedad en el oficio de Protho-Albeytar de esta Provincia», basándose en el hecho de que «es indubitable que en cada Provincia son diferentes los usos, costumbres y privilegios». Esta era una manifestación más de las dificultades que supondría la extensión del tribunal castellano a los territorios de la antigua Corona de Aragón. La Real Audiencia defendió, por tanto, el mantenimiento del status quo institucional en materia de regulación y control del ejercicio de los médicos, cirujanos, boticarios y albéitares. Además, para el caso específico de los albéitares, la Audiencia no sólo afirmó que la elección de protoalbéitar en Cataluña era un nombramiento real, sino también que en materia de leyes municipales y gremiales, los reyes borbónicos habían confirmado «los Privilegios, Usos y Costumbres de Cataluña [...] en las Cortes de los años 1725,1760 y $1789 \gg^{42}$. Esta compleja situación se mantuvo hasta bien entrado el siglo XIX ${ }^{43}$.

De acuerdo con lo hasta aquí referido, parece razonable concluir llamando la atención sobre dos cuestiones: por una parte, parece que las dificultades legislativas y ejecutivas que experimentó la organización de la albeitería se deberían relacionar con las ideas de necesidad y de utilidad política y económica del estado borbónico, en el contexto de la creación de la escuela de veterinaria de Madrid. Por otra, no parece comparable la política sanitaria borbónica en materia de albeitería con el interés, el esfuerzo inversor y la eficaz reforma administrativa que experimentó la cirugía en el contexto de la crea-

42 Sobre estos aspectos y sobre la declaración de la albeitería como arte liberal, véase: LLEONART, F. (1974f), «Instancia para real conocimiento de la Albeytería como profesión liberal, y para gozar de las mismas exenciones que los boticarios (1738)», Terapéutica Veterinaria Biohorm, 28, 376-83; DUALDE (1997), p. 147-153 y 192-93. Sobre el papel de la Real Audiencia catalana, véase: ACA, RA, Consultas, reg. 1160, 196v-199v, Barcelona 30/4/1795.

43 Puigvert SolÀ, J. M. (2002), «Els professionals de la sanitat a la Catalunya de mitjan segle XIX». En: Fradera, J. M. (coord.), Barcelona. Quaderns d'Història 6. Societat, política i cultura a Cataluña, 1830-1880, 173-188; PuigVERT SOLÀ, J. M. (2004), «De manescals a veterinaris. Notes per a una sociologia històrica de la professió veterinària a Catalunya», Estudis d'Història Agrària, 17, 729-750. 
ción de los Reales Colegios de Cirugía de Cádiz, Barcelona y Madrid. Este es un hecho que ya hemos señalado en otros trabajos para los casos de los médicos y los boticarios barceloneses del siglo XVIII. ${ }^{44}$ Volvamos de nuevo al punto de partida de este artículo: más allá de un marcado interés por la albeitería del ganado equino, desde las perspectivas de la nobleza y del ejército, convendría señalar otros aspectos que tuvieron un papel decisivo a la hora de desinteresar a las autoridades y de mantener el estado de las cosas, a pesar de las contradicciones y conflictos creados por las diferentes instituciones de la administración borbónica, entre los cuales cabe citar: la difícil situación de la ganadería española, la negativa visión de los agraristas ilustrados españoles sobre la ganadería, la decidida opción importadora de ganado, el escaso nivel científico de la albeitería en comparación con la de otros países europeos y la ausencia de una concepción agronomista y experimental de la medicina animal en los círculos médicos ilustrados. ${ }^{45}$

Fecha de recepción: 8 de febrero de 2006

Fecha de aceptación: 8 de octubre de 2006

44 ZARZoso (1996); ZARZOSO (2004), p. 63-142.

45 El análisis de estos factores y su proyección en los estudios y la organización de la albeitería a partir de un trabajo de historia comparada constituyen otro trabajo de investigación. Una primera aproximación se puede realizar a partir de los trabajos de CRAVOT (1999), p. 20-51 y 141-160 y los de HannawaY, C. (1972), «The Société Royale de Médecine and epidemics in the Ancien Régime» y «Veterinary medicine and rural health in pre-revolutionary France», Bulletin of the History of Medicine, 46, 257-273 y 51, 431-447 y (1981), «From private hygiene to public health: a transformation in western medicine in the eighteenth and nineteenth centuries». En: OGAWA, T. (ed.), Public Health, Tokio, the Tanigouchi Foundation, 108-128. 